\title{
O uso do Cabri 3D para desenvolver habilidade de visualização
}

\section{Guilherme Baggio Marin}

Centro Universitário Franciscano (UNIFRA)

prof.baggiomarin@gmail.com

\section{José Carlos Pinto Leivas}

Centro Universitário Franciscano (UNIFRA)

leivasjc@yahoo.com.br

\section{Resumo}

Este artigo é um recorte de uma dissertação de mestrado que teve como objetivo investigar as contribuições do software Cabri 3D na visualização de seções obtidas no cubo através de planos. A pesquisa foi realizada com alunos do ensino médio de uma escola particular de Santa Maria - RS, com 29 alunos do $3^{\circ}$ ano, todos de uma mesma turma, os quais foram voluntários. Foi empregada a metodologia investigativa na realização de dez atividades, nas quais os alunos realizaram seções no cubo utilizando lápis e papel. Posteriormente, realizaram essas mesmas atividades usando o software Cabri 3D. A coleta de dados foi feita pelos registros dos alunos em lápis e papel e pelas gravações digitais dos trabalhos no computador, no qual desenvolveram seus trabalhos, por meio das representações geométricas e utilizando, na mesma tela, o recurso do software "nova vista de texto". O artigo aborda a primeira dessas atividades e comprovou que o uso do Cabri 3D apresentou considerável desenvolvimento de habilidades visuais, bem como de argumentações relativas às construções geométricas realizadas.

Palavras-chave: Cabri 3D. Ensino de Geometria Espacial. Seções em Cubos. Visualização. Ensino Médio.

\section{Using Cabri 3D to develop visualization ability}

\begin{abstract}
This article is part of a dissertation which aimed to investigate the contributions of the software Cabri3D in the visualization of sections obtained from the cube by planes. The research was performed by 29 high school students in the 3rd year of a private school in Santa Maria, Rio Grande do Sul state, all volunteers from a same class. The research methodology was used in the realization of ten activities, in which students made sections in the cube using pencil and paper and, later, they performed these same activities using the software Cabri3D. Data collection was made by student records in pencil and paper and, also, by the digital recordings of the work on the computer in which they developed their work, by mean of geometric representations and also using at the same screen, the software feature "new text view". The article reports the first of these activities and it proved that the use of Cabri 3D showed considerable development of visual abilities, as well as arguments concerning the geometric constructions made.
\end{abstract}

Keywords: Cabri 3D. Teaching of Space Geometry. Sections of Cubes. Visualization. High School. 


\section{Introdução}

O ensino da geometria vem tentando se reerguer após o Movimento da Matemática Moderna, na década de 1970, quando a álgebra ganhou destaque, fazendo com que a geometria fosse, de certa forma, esquecida nos currículos das escolas. Alguns autores, como Souza (2001) e Fontes \& Fontes (2010), afirmam que o ensino da geometria não tem oferecido subsídios para que os alunos formulem conjecturas e superem suas dificuldades. A pesquisa de Gazire (2000), dentre outros resultados, apontou que a apresentação de uma geometria sistematizada não conseguiu influir para que ela permanecesse no currículo.

Esses fatos foram motivacionais para procurarmos abordar o uso da informática no ensino de geometria espacial, investigando quais as contribuições que o software Cabri 3D pode oferecer para o desenvolvimento da habilidade de visualização de seções obtidas em cubos por um plano que interseccione suas arestas. Dessa forma, investigamos, descrevemos e interpretamos os processos de construção usados pelos alunos.

A pesquisa que deu origem à dissertação de mestrado ocorreu em duas partes: na primeira, os alunos realizaram seções planas na representação de um cubo, usando apenas papel e lápis; já na segunda, desenvolvida no laboratório de informática, os alunos realizaram as mesmas atividades, porém com o auxilio do programa Cabri 3D. Lembramos que o Cabri 3D é um software pago, portanto usamos uma versão teste, que oferece todas as funções habilitadas pelo período de trinta dias. Podemos encontrar essa versão do software no link http://www.cabri.com/download-cabri-3d. html. Os dados coletados foram confrontados, para obtermos uma conclusão sobre a eficácia ou não do software nas atividades didáticas propostas.

Neste artigo, apresentamos um recorte da dissertação de mestrado, na qual analisamos a primeira das dez atividades realizadas, estabelecendo um confronto entre as duas partes, a fim de comprovar a eficácia do uso da tecnologia empregada.

\section{Visualização e geometria dinâmica}

O termo visualização, associado às habilidades visuais é, de certa forma, recente na literatura matemática no sentido apontado por Leivas (2009, p.22): "um processo de formar imagens mentais, com a finalidade de construir e comunicar determinado conceito matemático, com vistas a auxiliar na resolução de problemas analíticos ou geométricos". É frequentemente relacionado ao uso do órgão da visão, quando alguém deseja expressar o fato de estar vendo algum objeto que se encontra ao alcance de seus olhos.

Podemos pensar, também, no processo de visualização como uma forma de verificar a capacidade que as pessoas têm para realizar tarefas que exigem imaginação 
e intuição mentais de objetos espaciais, muitas vezes, fora do alcance visual, com a finalidade de realizar operações geométricas a serem feitas com tais objetos. Algumas vezes, esses objetos estão ao alcance dos indivíduos apenas em representações desenhadas em papel, nem sempre possibilitando a real interpretação dos mesmos.

Para Piaget e Inhelder (apud Presmeg 2006, p. 2), o termo visualização é usado quando se cria uma imagem visual na mente da pessoa a respeito de um determinado arranjo espacial. Sobre a mesma habilidade, Presmeg (2006) afirma que visualização é usada para incluir processos de construção e transformação de imagens visuais, mentais e todas as construções de natureza espacial que podem ser implicadas ao fazer Matemática.

Arcavi (1999) afirma que visualização é a habilidade, o processo e o produto de criação, interpretação, bem como o uso de comentários sobre figuras, imagens e diagramas em nossas mentes, em papéis ou através de ferramentas tecnológicas, com a finalidade de desenhar e comunicar informações.

Encontramos guarida no trabalho desse autor para empregamos, em nossa pesquisa, a geometria dinâmica, a fim de investigar como ocorrem essas construções em cortes realizados, por um plano, num cubo, utilizando os recursos do Cabri $3 \mathrm{D}$. Acreditamos que o software pode auxiliar no tratamento e na visualização de figuras e propriedades de objetos espaciais, permitindo que os estudantes formem conjecturas a respeito das propriedades das figuras, já que podem explorá-las em diferentes pontos de vista.

A falta ou pouca habilidade de visualização cria uma barreira na aprendizagem de conceitos de geometria espacial, inclusive em disciplinas de cursos que necessitam dessa habilidade, como as engenharias, arquitetura, desenho industrial, entre outras. As tecnologias, em nosso entender, são ferramentas poderosas para eliminar tais barreiras, quando utilizadas de forma adequada.

A denominada "revolução informática" promove mudanças radicais na área do conhecimento, que passa a ocupar um lugar central nos processos de desenvolvimento em geral. É possível afirmar que, nas próximas décadas, a educação vá se transformar mais rapidamente do que em muitas outras, em função de uma nova compreensão teórica sobre o papel da escola, estimulada pela incorporação das novas tecnologias. (BRASIL, 2000, p.5)

Almeida (2010) afirma que o Cabri 3D não possui apenas ferramentas matemáticas que permitem construir poliedros, mas oferece também a vantagem de manipular diretamente suas representações sob diferentes ângulos, favorecendo a visualização de objetos tridimensionais. 
Segundo Jahn e Bongiovanni (2008, p. 1), “O Cabri 3D é um software de geometria dinâmica que, além de preservar as propriedades de objetos geométricos tridimensionais quando manipulados, permite também mudar o ponto de vista em relação ao objeto representado".

Podemos perceber que os autores destacam "mudar o ponto de vista", referindo-se não apenas ao recurso de rotacionar o objeto em $360^{\circ}$, mas também à maneira de conceber esse objeto, identificando propriedades antes não percebidas, ou seja, enxergar com outros olhos.

Seguindo essas concepções sobre visualização e tecnologia computacional, desenvolvemos a pesquisa a seguir descrita.

\section{A pesquisa realizada}

A pesquisa foi realizada com uma turma de 29 alunos de uma escola de Ensino Médio da cidade de Santa Maria, no Rio Grande do Sul, na qual o mestrando é o professor titular e teve como problema de pesquisa: quais são as contribuições do software Cabri 3D na visualização de seções planas no cubo? A fim de responder ao problema, seguimos o seguinte objetivo: investigar quais são as contribuições do software Cabri 3D como ferramenta auxiliadora na visualização de seções planas em cubos.

A metodologia de pesquisa é de cunho investigativo, sendo que os dados coletados são de natureza qualitativa e de caráter exploratório, segundo as concepções de Bogdan e Biklen (apud Lüdke e André 1986), pois tivemos o cuidado em estimular os estudantes a pensarem livremente sobre atividades planejadas cuidadosamente pelo investigador. Os investigados as realizaram no próprio ambiente de sala de aula, na escola que frequentam, e sobre um tema curricular a ser desenvolvido.

Os dados coletados têm características descritivas, são ricos em descrições individuais favorecendo ao investigador analisar o significado dado ao processo pelos alunos e a forma como eles encaram a situação problema proposta. Por fim, ao analisar os dados coletados, houve um processo de interpretação indutiva, para elaborarmos conclusões sobre a evolução na aquisição das habilidades visuais com o uso do Cabri 3D.

Para desenvolver a pesquisa, foram propostas dez atividades para os alunos realizarem, inicialmente, fazendo uso de instrumentos convencionais de desenho. Posteriormente, as mesmas tarefas foram realizadas com o uso do Cabri 3D. Das mesmas, foi escolhida para este artigo a primeira, cujos registros foram entregues ao investigador para análise posterior. Os registros da realização no Cabri 3D foram feitos usando o recurso "nova vista de texto" que o software oferece e salvos numa pasta do computador que os alunos utilizavam e, depois, encaminhadas ao investigador para análise. 
As transcrições feitas pelos investigados e aqui apresentadas são literais, sem intervenção do investigador quanto a sua forma, tanto de língua portuguesa, quanto de conceituação matemática.

\section{Atividade realizada com lápis e papel}

Para realização da atividade com lápis e papel foi feita uma apresentação de um esqueleto de cubo por meio de suas arestas. Solicitamos que os alunos fizessem um corte do mesmo por um plano, de modo a obter uma região triangular de lados diferentes (triângulo escaleno), seguido de um pedido para desenharem e descreverem a construção realizada.

Tínhamos como expectativa para a realização dessa atividade que os alunos obtivessem uma construção como a da figura 1. Nessa representação, o plano sector intercepta três faces e três arestas do cubo, formando uma região triangular de lados diferentes. Para isso, os pontos de interseção do plano sector (I, J e K) com as arestas $\mathrm{AD}, \mathrm{DC}$ e $\mathrm{DH}$, respectivamente, devem ter distâncias diferentes ao vértice $\mathrm{D}$, que é comum às três arestas.

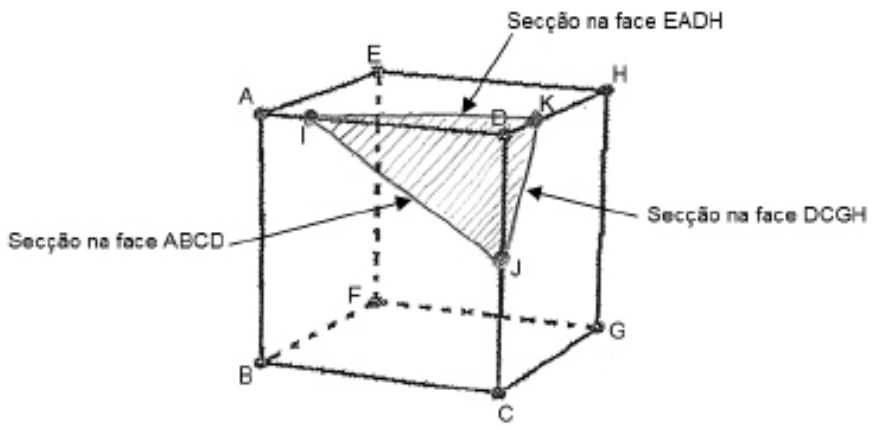

Figura 1: construção realizada pelo investigador para a atividade. Fonte: dissertação.

O quadro 1, apresentado a seguir, é constituído pela análise dos dados referentes à atividade desenvolvida pelos 29 alunos da turma. Eles foram separados nas seguintes categorias:

$\mathrm{A}=$ alunos que conseguiram realizar a seção solicitada;

$\mathrm{B}=$ alunos que conseguiram realizar parcialmente a seção solicitada;

$\mathrm{C}=$ alunos que realizaram outra construção;

$\mathrm{D}=$ alunos que deixaram a atividade em branco. 
Quadro 1. Distribuição de alunos por categorias de respostas.

\begin{tabular}{|l|l|l|l|l|}
\hline Categoria & A & B & C & D \\
\hline $\mathrm{N}^{\mathrm{o}}$ de Alunos & 5 & 2 & 21 & 1 \\
\hline Justificaram & 4 & 1 & 18 & 0 \\
\hline Não Justificaram & 1 & 1 & 3 & 1 \\
\hline
\end{tabular}

Essa distribuição é mostrada no gráfico circular abaixo em termos percentuais.

Gráfico 1. Distribuição das categorias. Elaboração dos autores.

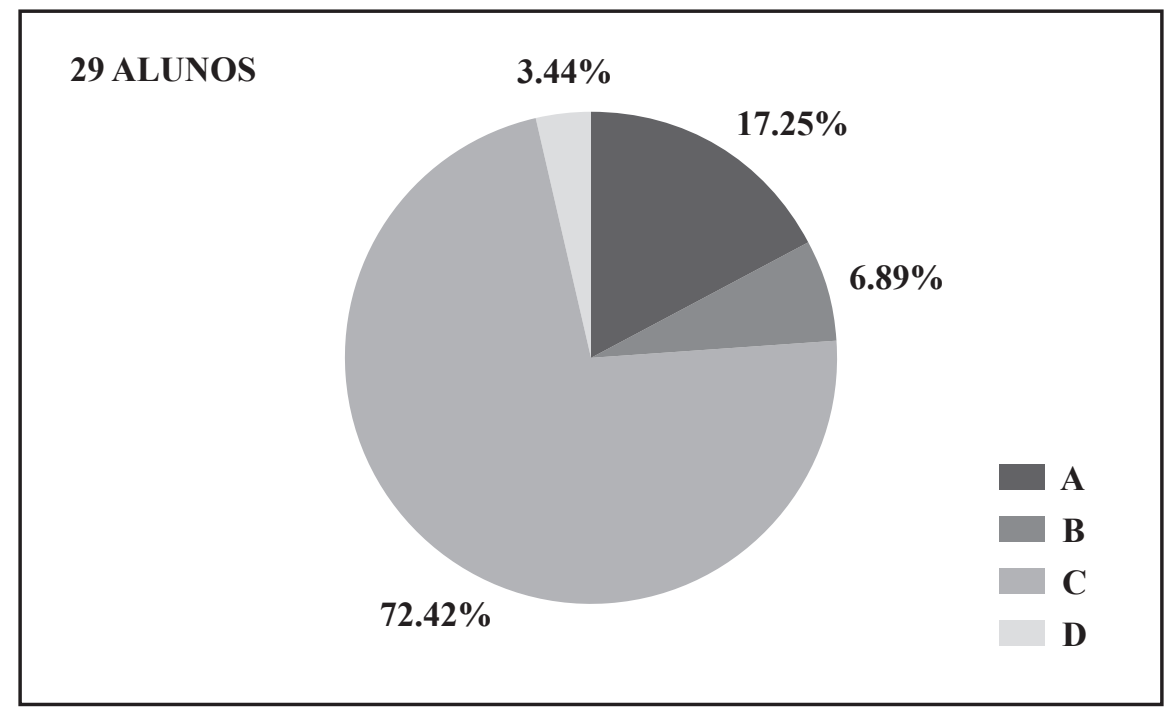

Categorizamos, no quadro 1, e ilustramos, no gráfico 1, com o código "A", os alunos que conseguiram fazer a seção pedida, ou seja, que seccionaram e representaram corretamente o corte. Os dados mostram que apenas 5 alunos ou 17,25\% dos que participaram da pesquisa conseguiram representar o corte corretamente, como, por exemplo, o aluno 5 (figura 2). 


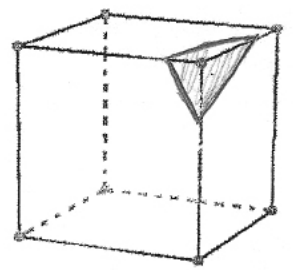

Figura 2: construção realizada pelo aluno 5. Fonte: dissertação de mestrado.

O aluno fez sua construção de maneira correta, de acordo com o esperado. A representação do corte foi feita com linhas cheias, pois escolheu fazê-la de forma que o observador se encontrasse na parte frontal do cubo, o que indica ter boa noção de perspectiva. Embora se perceba que visualizou o corte, não conseguiu explicar perfeitamente como o fez, não deixando claro o critério de escolha das arestas. Sua justificativa foi: passar o plano cortando três arestas em pontos diferentes destacando um vértice. (aluno 5). Percebemos que, para obter uma região triangular de lados diferentes, o aluno considerou pontos em posições diferentes nas arestas, ou seja, com distâncias diferentes do vértice comum, demonstrando ter conhecimentos pertinentes à geometria.

Os outros alunos enquadrados na categoria A realizaram construções semelhantes.

Categorizamos, no quadro 1, complementado pelo gráfico 1, com o código "B", os alunos que conseguiram fazer parcialmente a construção, ou seja, conseguiram seccionar uma região triangular, porém não aquela pedida no enunciado da atividade ou, então, aqueles que erraram na perspectiva do corte. Apenas 2 ou $6,89 \%$ dos participantes se enquadraram nessa categoria de respostas. $\mathrm{O}$ aluno 28 é um deles e sua representação (figura 3) é justificada da seguinte forma: passei uma reta por 3 pontos. Ele obteve uma região triangular equilátera cujos lados são diagonais de três faces consecutivas duas a duas. Podemos ver que visualizou o corte a ser feito, mas não levou em consideração o conceito de triângulo escaleno, pois obteve um triângulo equilátero. Também podemos observar que o aluno escolheu a parte frontal do cubo e que as linhas do corte são cheias, o que nos leva a intuir que o aluno tem alguma noção de perspectiva.

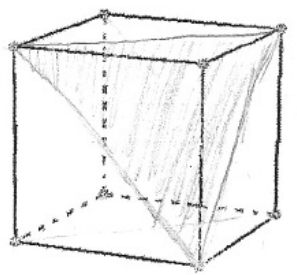

Figura 3: construção realizada pelo aluno 28 para a atividade 1. Fonte: dissertação. 
Outra construção a ser analisada, representada na figura 4, é a do aluno 29. Ele não a justifica, mas consegue seccionar o cubo de forma a obter uma região triangular. Ainda podemos ver que ele escolhe uma visão lateral do cubo, o que torna o erro da perspectiva mais nítido, assim como seu desenho mostra uma linha tracejada na face superior, onde deveria ser linha cheia, por ser uma face visível. Podemos destacar que o aluno sombreou o sólido obtido com a seção e não a região plana solicitada na atividade. Esse fato nos leva a intuir que ele não faz distinção entre região plana e espacial.

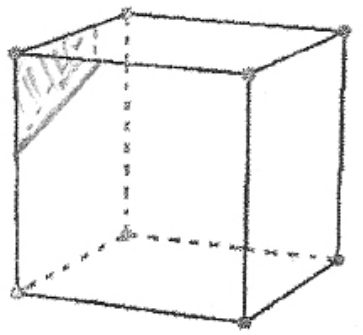

Figura 4: construção realizada pelo aluno 29. Fonte: dissertação.

Categorizamos, no quadro 1, com o código "C", os alunos que fizeram outra construção, ou seja, as seções que não formam regiões ou que formam regiões diferentes da pedida no enunciado da atividade. Nessa categoria, encontramos a maioria dos alunos, ou seja, $72,42 \%$ das respostas. Escolhemos as representações dos alunos 1, 7, 25, 23 e 19, por serem distintas entre si, sobre as quais teceremos nossos comentários. As outras construções são similares a essas.

O aluno 1 considera como região solicitada na atividade, aquela formada por duas arestas que compõem uma face e a diagonal dessa (figura 5), argumentando que, ao cortar na vertical com retas perpendiculares, obtemos um triângulo. Podemos intuir de sua representação e justificativa que o mesmo não entendeu o que foi solicitado, pois não há correspondência alguma entre sua justificativa e a construção feita.

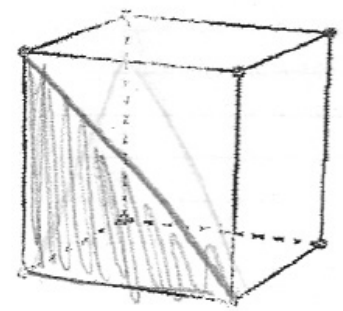

Figura 5: construção realizada pelo aluno 1. Fonte: dissertação. 
O aluno 7 faz a representação dada na figura 6 e numera três vértices que julga corresponderem ao triângulo obtido pelo corte. Entretanto, ele não percebe que o plano contendo os vértices 1 e 2 , ou seja, a aresta $1-2$, não tem como tocar somente a 3 ou somente a 4 . O plano cortaria a aresta $3-4$ e, dessa forma, formaria uma região retangular e não uma triangular.

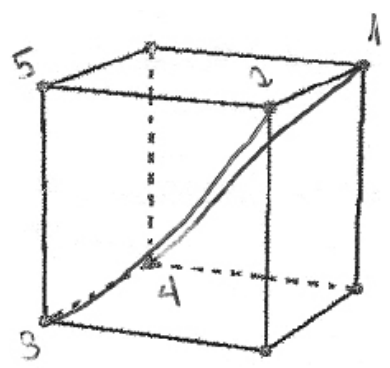

Figura 6: construção realizada pelo aluno 7. Fonte: dissertação.

Corte similar foi feito pelo aluno 25, representado na figura 7 que, mesmo sombreando a região quadrangular, compreende como região triangular aquela que representa na sua justificativa. Percebemos, com base na construção do aluno que, apesar de sombrear a região retangular obtida pela seção, o mesmo não compreende que ela deve estar contida no plano de corte.
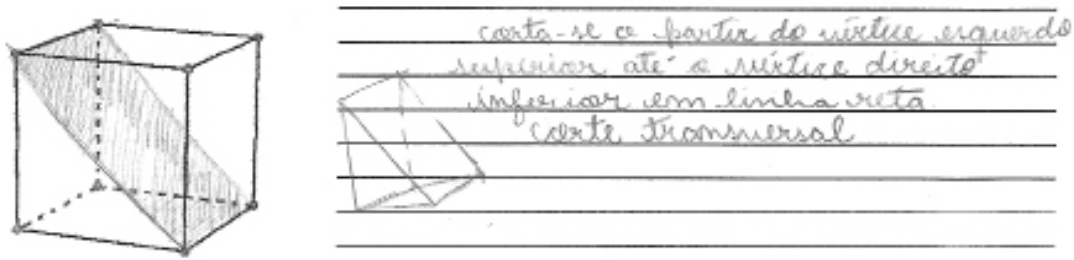

Figura 7: construção e justificativa realizada pelo aluno 25. Fonte: dissertação.

O aluno 23 faz a representação dada na figura 8, na qual há uma seção horizontal, mas ele não visualiza que esse corte, na realidade, formaria uma região quadrangular. Podemos ver na figura que a região triangular encontrada por ele corresponde à metade da região quadrangular obtida pelo plano de corte e que, para obter essa região, seria necessário seccionar o cubo mais de uma vez, o que não estaria de acordo com a atividade proposta. $\mathrm{O}$ aluno não justificou sua construção. 


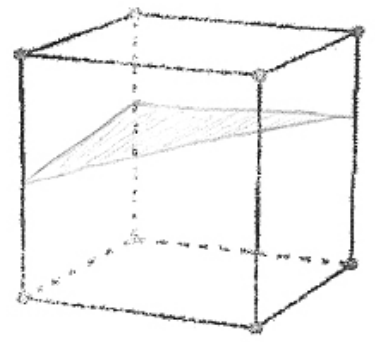

Figura 8: construção realizada pelo aluno 23. Fonte: dissertação.

Já o aluno 19, cuja representação da atividade consta na figura 9, entende como região triangular aquela formada entre duas arestas consecutivas da face superior do cubo e a aresta formada pela seção do plano de corte com o cubo. Sua justificativa é a seguinte: cortei as duas arestas superiores chegando às arestas inferiores. Percebemos a região sombreada na figura como sendo, em sua visualização, a região triangular de lados diferentes.

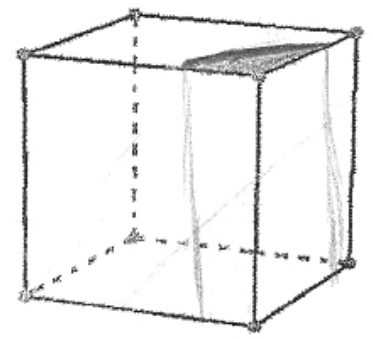

Figura 9: construção realizada pelo aluno 19. Fonte: dissertação.

Na sequência do artigo, apresentaremos a mesma atividade realizada com lápis e papel, porém realizada com o uso do software. Seguiremos o mesmo procedimento, agora analisando as respostas dos estudantes oriundas dos registros digitais feitos pelos mesmos na mesma tela em que realizaram os cortes, pois entendemos dar maior fidedignidade à pesquisa, não se perdendo dados na transcrição.

\section{A atividade realizada com o auxílio do Cabri 3D:}

Nessa atividade, o esperado era que os alunos se apossassem das ferramentas e recursos do software para fazer os cortes, manipular as figuras e, dessa forma, visualizar as seções obtidas e fazer as justificativas usando a ferramenta "nova vista 
texto", disponível no Cabri 3D. A partir dessa etapa torna-se possível comparar as atividades e verificar a contribuição oferecida pela geometria dinâmica do software.

Para a atividade apresentada neste artigo, procedemos ao encaminhamento a seguir descrito.

Construa um cubo com uma das faces no plano base. Use a ferramenta "Recorte de Poliedro" corte o cubo por um plano de maneira a obter uma região triangular de lados diferentes (triângulo escaleno). No menu documento, abra uma "Nova vista texto" e descreva sua construção. Salve o arquivo com o nome Fulano_atividade_1 na pasta "Registro", que se encontra na área de trabalho.

Com essa atividade esperávamos que os alunos passassem o plano sector pelos pontos I, J e K, os quais são pontos sobre as arestas $\mathrm{AD}$, DC e DH, respectivamente, com distâncias diferentes ao vértice $\mathrm{D}$, pois haviam realizado a mesma com outro recurso didático. Dessa forma, obteriam uma região triangular de três lados diferentes, como mostram as figuras 10 e 11. Na primeira delas, é construído o cubo e demarcados os pontos nas arestas, enquanto na segunda é pintada em laranja a região resultante do corte.

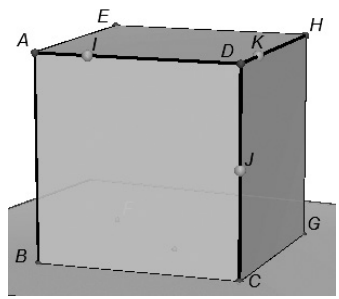

Figura 10: construção realizada pelo investigador usando o software Cabri 3D.

Fonte: dissertação.

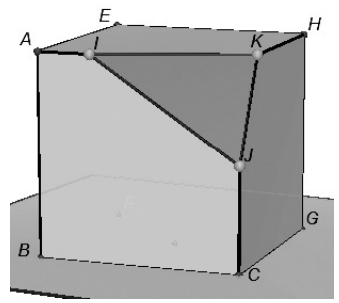

Figura 11: construção realizada pelo investigador usando o software Cabri 3D.

Fonte: dissertação.

No que segue, apresentamos um quadro demonstrativo no qual categorizamos as respostas dos alunos quanto à resolução da atividade utilizando o Cabri 3D. 
Quadro 2. Distribuição de alunos por categorias de respostas à atividade realizada com o auxílio do software Cabri 3D.

\begin{tabular}{|l|l|l|l|l|}
\hline Categoria & A & B & C & D \\
\hline $\mathbf{N}^{0}$ de Alunos & 26 & 1 & 0 & 2 \\
\hline Justificaram & 26 & 1 & 0 & 1 \\
\hline Não Justificaram & 0 & 0 & 0 & 1 \\
\hline
\end{tabular}

Essa distribuição é mostrada no gráfico circular abaixo em termos percentuais.

Gráfico 2. Distribuição das categorias. Construção dos autores.

29 ALUNOS

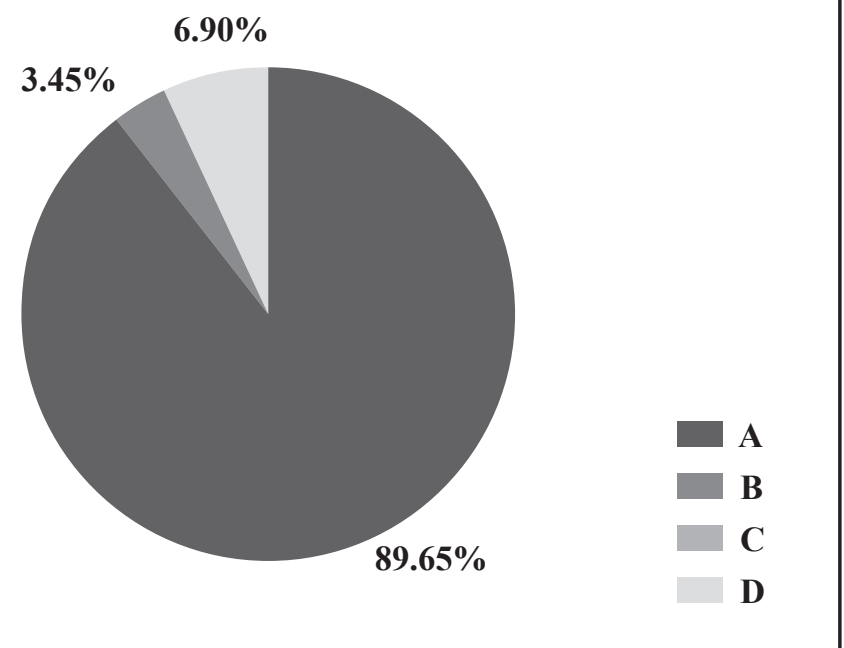

Podemos perceber, pelo quadro 2, que 26 alunos conseguiram realizar a construção com o auxílio do software Cabri 3D e isso corresponde a 89,65\% dos participantes da pesquisa. Comparando com os $17,25 \%$ da mesma atividade realizada no papel e lápis (quadro 1), podemos concluir que houve uma melhora na visualização do corte.

Na categoria A, encontramos o aluno 2, o qual fez a construção representada na figura 12. Além de explicar como fez o seu corte, o estudante ainda deu seu parecer espontâneo sobre o software Cabri 3D, indicando que ele pode ser um facilitador na visualização de seções em sólidos geométricos. Isso ratifica o 
fato apontado por Presmeg (2006) sobre essa habilidade ser usada para incluir processos de construção e transformação de imagens visuais, mentais e construções espaciais envolvidas no fazer matemático.

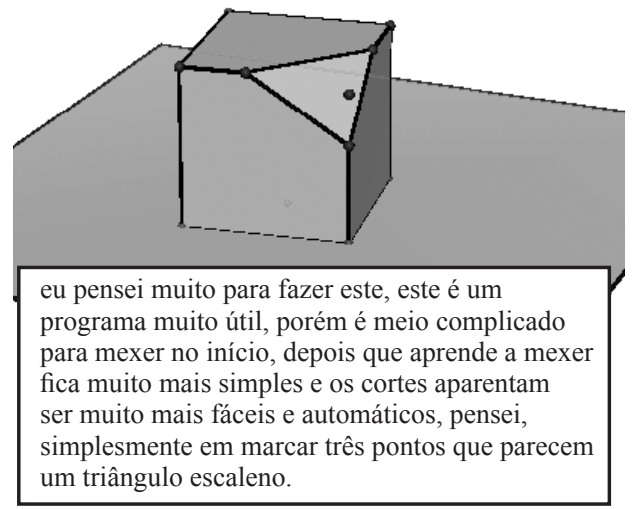

Figura 12: construção realizada pelo aluno 2 com o auxílio do software Cabri 3D.

Fonte: dissertação.

$\mathrm{Na}$ categoria $\mathrm{B}$, temos um único representante, o que equivale a 3,45\% dos participantes da pesquisa. Em sua construção (figura 13), ele passa o plano sector por três pontos aleatórios sobre três arestas que concorrem em um mesmo vértice, mas marca dois pontos com a mesma distância desse vértice comum. Dessa forma, obtém como região um triângulo isósceles e não um escaleno, como fora solicitado na atividade. Muito embora o construto realizado não esteja correto, não deixamos de reforçar a importância da criação de alternativas de solução para o problema formulado pelo investigador, importância essa destacada por Fagundes e Hoffman (2002).

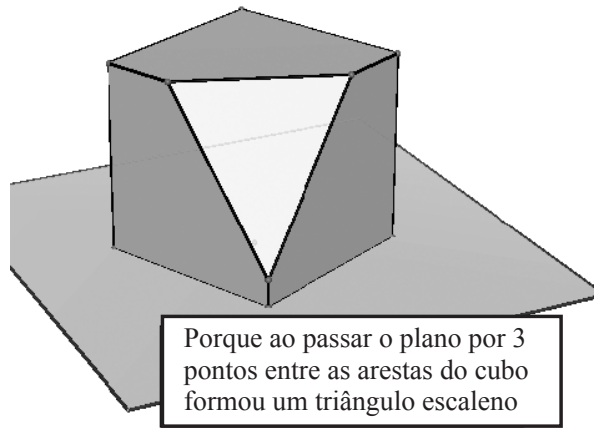

Figura 13: construção realizada pelo aluno 1 com o auxílio do software Cabri.

Fonte: dissertação. 
Na categoria C, não temos nenhum representante.

Podemos ver, na figura 14, que o aluno 4 justificou, mas não conseguiu fazer nenhuma seção no cubo. Esse aluno se enquadra na categoria D.

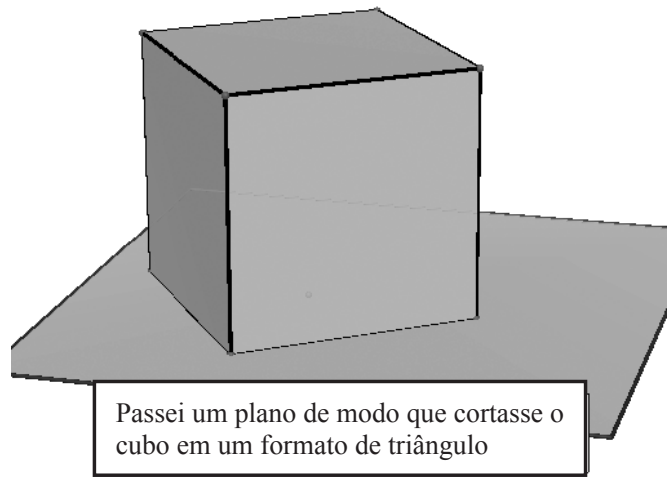

Figura 14: construção realizada pelo aluno 4 com o auxílio do software Cabri 3D.

Fonte: dissertação.

\section{Consideração finais}

$\mathrm{O}$ artigo aqui apresentado é uma pequena parte de uma pesquisa realizada em um Mestrado Profissional em Ensino de Matemática, no qual propusemos investigar o uso da informática para levar uma tecnologia ao ensino de geometria para dentro da sala de aula. Mais precisamente, propusemos um ambiente de interação entre o computador e os alunos, usando o software Cabri 3D, apesar de ser pouco conhecido em ambientes escolares, por não ser um software livre, mas que possui um desempenho reconhecido mundialmente.

Muito embora tenham sido realizadas dez atividades, com lápis e papel, para poder estabelecer comparativos, não teríamos como apresentá-las em um único artigo. Por isso optamos pela escolha de uma delas e por detalhar todo o procedimento investigativo.

A abordagem tradicional da geometria espacial, que ainda hoje se restringe à medida do cálculo de áreas e volumes dos sólidos, não é satisfatória para explicar o "mundo geométrico" em que vivemos. As formas encontradas em projetos arquitetônicos, por exemplo, já não podem ser tratadas com descaso. Elas devem receber uma atenção especial, pois existem formas geométricas espaciais obtidas apenas por relações entre figuras planas e espaciais e é nesse ponto que a informática aparece como uma grande aliada.

Entendemos que o ensino da geometria deve aflorar essas questões nos alunos, possibilitando-lhes discuti-las e analisá-las para desenvolver o raciocínio de forma mais completa. 
Por meio dos dados coletados na investigação, concluímos que as maiores dificuldades dos alunos quanto às construções foram as descritas a seguir.

1) Visualização das figuras espaciais representadas no plano.

2) Conceitos básicos de geometria plana e espacial.

3) Representação de linhas em perspectiva de objetos espaciais no plano.

4) Argumentação e justificativa quanto às suas construções.

5) Estratégias de construção.

A investigação nos permitiu concluir que os alunos justificam informalmente suas construções, mas não conseguem passar essas justificativas para o modelo formal de forma convincente. Acreditamos que essa dificuldade em justificar ou argumentar sobre suas construções é uma herança que o aluno traz consigo desde o início de sua atividade escolar, pois são estimulados a repetir a "receita do bolo" ensinada há anos, sem ao menos entender o porquê da ordem dos "ingredientes".

Segundo Nacarato et. al. (2009), há certo consenso entre os pesquisadores de que os alunos necessitam ser preparados para dominar o processo dedutivo e um dos caminhos apontados para isso é o da argumentação. Os autores ainda afirmam que uma argumentação satisfatória tem que ser construída gradativamente pelos alunos, o que exige instrução adequada a ser ministrada pela escola básica, cabendo a ela encaminhá-los para o domínio do processo dedutivo.

Quanto à utilização das ferramentas disponibilizadas pelo software, podemos afirmar que elas pouco foram exploradas pelos alunos. Mesmo com ferramentas de precisão, a grande maioria ainda optou por fazer as construções "a olho", o que levou muitos ao erro em suas construções. Apesar disso, podemos afirmar que o software trouxe muitas contribuições para a visualização das seções no cubo.

Da análise realizada e dos relatos dos alunos, identificamos algumas contribuições do software no desenvolvimento da visualização de seções em cubos, como:

1) facilidade de trabalho no ambiente Cabri 3D, muito embora a falta de experiência e conhecimento dos alunos sobre o mesmo;

2) facilidade na visualização dos sólidos e, consequentemente, das seções;

3) praticidade em suas ferramentas e recursos visuais como a da rotação do objeto em $360^{\circ}$;

4) possibilidade de manipular os objetos livremente, fazer e desfazer as construções quantas vezes forem necessárias. 
A análise feita indicou que 5 ou 17,25\% dos estudantes realizaram a atividade corretamente quando utilizaram a construção com os recursos tradicionais - lápis e papel. Por sua vez, ao realizarem a atividade no Cabri 3D, o número de alunos que acertaram passou para 26 alunos ou 89,65\% e esses números, por si só, nos dão a certeza da relevância do uso do Cabri 3D na obtenção de seção triangular escalena em um cubo por um plano.

Os dados evidenciaram que o software Cabri 3D facilitou a percepção da perspectiva das figuras, permitindo aos alunos explorarem o objeto em vários pontos de vista, favorecendo uma melhor visualização dos cortes, procedendo em um aumento no número de acertos nas atividades. Entendemos que o objetivo traçado para a investigação de verificar as contribuições do software Cabri 3D na visualização de seções planas em cubos foi cumprido, muito embora tenhamos aqui dado um pequeno demonstrativo disso.

\section{Referências}

ALMEIDA, T. C. S. Sólidos arquimedianos e CABRI 3D: um estudo de truncaduras baseadas no renascimento. Dissertação (Mestrado Profissional em Ensino de Matemática) - Pontifícia Universidade Católica de São Paulo, São Paulo, 2010.

ARCAVI, A..The role of visual representation in the learning of mathematics. In: NORTH AMERICAN CHAPTER OF THE PME, 1999. Proceedings... Disponívelem: <http://www.clab.edc.uoc.gr/aestit/4th/PDF/26.pdf>. Acesso em: 30 set. 2008.

BRASIL. Ministério da Educação. Secretaria de Educação. Parâmetros Curriculares Nacionais (Ensino Médio). Brasília, 2000.

FAGUNDES, L.; HOFFMAN, D. A informática educacional na escola pública. (FUTURA), disponível em <http://www.futura.org.br/wp-content/uploads/2011/09/A-informatica-educacional-na-escola-publica.pdf $>$. Acessado em: 21 jul 2013.

FONTES, M.de M. \& FONTES, D. J. S. Utilização do Software GeoGebra no Ensino de Geometria. In: ENCONTRO NACIONAL DE ENSINO DE MATEMÁTICA, X. Anais... Salvador - BA, 2010.

GAZIRE, E.S. O não resgate das geometrias. 2000. Tese (Doutorado em Educação) - Faculdade de Educação da Universidade Estadual de Campinas. Campinas: SP. [s.n.], 2000. 
JAHN, A. P.; BONGIOVANNI, V. Explorações em geometria especial com o software Cabri 3D, IV Colóquio de História e Tecnologia no Ensino da Matemática (htem), 5 a 9 de maio, Anais... Rio de Janeiro, Brasil, 2008.

LEIVAS, J. C. P. Imaginação, Intuição e Visualização: a riqueza de possibilidades da abordagem geométrica no currículo de cursos de licenciatura de matemática. 2009. Tese (Doutorado em Educação) - Universidade Federal do Paraná. Curitiba, 2009, $294 \mathrm{p}$.

LÜDKE, M.; ANDRÉ, M.E.D. A. Pesquisa em educação: abordagens qualitativas. São Paulo: EPU, 1986.

NACARATO, A. M.; GRANDO, R. C.; COSTA, J. L. Um contexto de trabalho colaborativo possibilitando a emergência dos processos de argumentação e validação em geometria.Acta Scientiae, v. 11, n.2, jul./dez. 2009.

PRESMEG, N. Research on visualization in learning and teaching mathematics. Disponível em: <http://www.kaputcenter.umassd.edu/downloads/symcog/bib/ pmeVisualizationFinalAPA.pdf $>$. Acessado em: 21 jul 2013.

SOUZA, F. S. Movimento da matemática moderna no Brasil: avanço ou retrocesso. Dissertação de Mestrado. PUCRJ, 2001.

Submetido em setembro de 2013 Aprovado em outubro de 2013 